\title{
Seasonal variability of mesoscale eddies of the Lofoten Basin using satellite and model data
}

\author{
V. S. Travkin ${ }^{1}$ and T. V. Belonenko ${ }^{1}$ \\ Received 2 April 2019; accepted 24 June 2019; published 5 October 2019.
}

The Lofoten Basin in the Norwegian Sea is the area where the warm Atlantic Water exhibits the greatest loss of heat than anywhere else in the Nordic Seas. It is called a "hot spot" of the Nordic Seas because of its high intense mesoscale eddy activity. Mesoscale eddies contribute significantly to the total oceanic heat and salt transport by advective trapping, stirring and mixing, and thus play an important role in the heat and salt balance of the region. A purpose of this study is to examine seasonal variability of mesoscale eddies in the Lofoten Basin using satellite altimetry data and GLORYS reanalysis. Satellite altimetry is used to track individual eddies, and co-located vertical profiles based on GLORYS data allow to study thermohaline characteristics inside the eddy cores. We analyze numbers of cyclonic and anticyclonic eddies in the Lofoten Basin using an eddy identification and tracking algorithm and demonstrate that the occurrences of eddies depend strongly on the season. We analyze seasonal variability of temperature, salinity, and potential density anomalies in zonal sections across the core of the Lofoten Vortex and explore spatial variability of thermohaline characteristics of mesoscale eddies at the depth of $450 \mathrm{~m}$ in different seasons. KEYWORDS: Lofoten Basin; Norwegian Sea; mesoscale eddies; altimetry; automatic detection.

Citation: Travkin, V. S. and T. V. Belonenko (2019), Seasonal variability of mesoscale eddies of the Lofoten Basin using satellite and model data, Russ. J. Earth. Sci., 19, ES5004, doi:10.2205/2019ES000676.

\section{Introduction}

The Lofoten Basin (LB) is a topographic depression of about $3250 \mathrm{~m}$ deep, bounded by the Vøring Plateau in the south, Mohn's Ridge in the northwest, and the Eurasian continental shelf in the east (Figure 1). This makes the LB quite a separate topographic formation with specific features of large-scale ocean circulation. The LB is bordered by the two main branches of the Norwegian Atlantic Current (NwAC) - the Norwegian Atlantic Slope Current (NwASC) and the Norwegian

\footnotetext{
${ }^{1}$ Saint Petersburg State University, Saint Petersburg, Russia

Copyright 2019 by the Geophysical Center RAS. http://rjes.wdcb.ru/doi/2019ES000676-res.html
}

Atlantic Frontal Current (NwAFC). The NwASC flows along the continental slope while the NwAFC follows the Mohn's Ridge along the 2000-2500 m isobaths. The NwASC is about two times stronger than the NwAFC [e.g. Mork and Skagseth, 2010, and it has a prominent seasonal cycle that has been linked to wind forcing [Jakobsen et al., 2003; Mork and Skagseth, 2010, Skagseth et al., 2015]. Being a transit area for the warm and saline Atlantic Water on its way to the Arctic Ocean, the LB plays an important role in sustaining the Meridional Overturning Circulation, for it is a region, where the Atlantic Water loses its heat to the atmosphere and mixes with surrounding water [Jakobsen et al., 2003, Koszalka et al., 2011, Mork and Skagseth, 2010; Poulain et al., 1996; Richards and Straneo, 2015, Rossby et al., 2009b. The LB is the deepest and broadest reservoir of Atlantic Wa- 


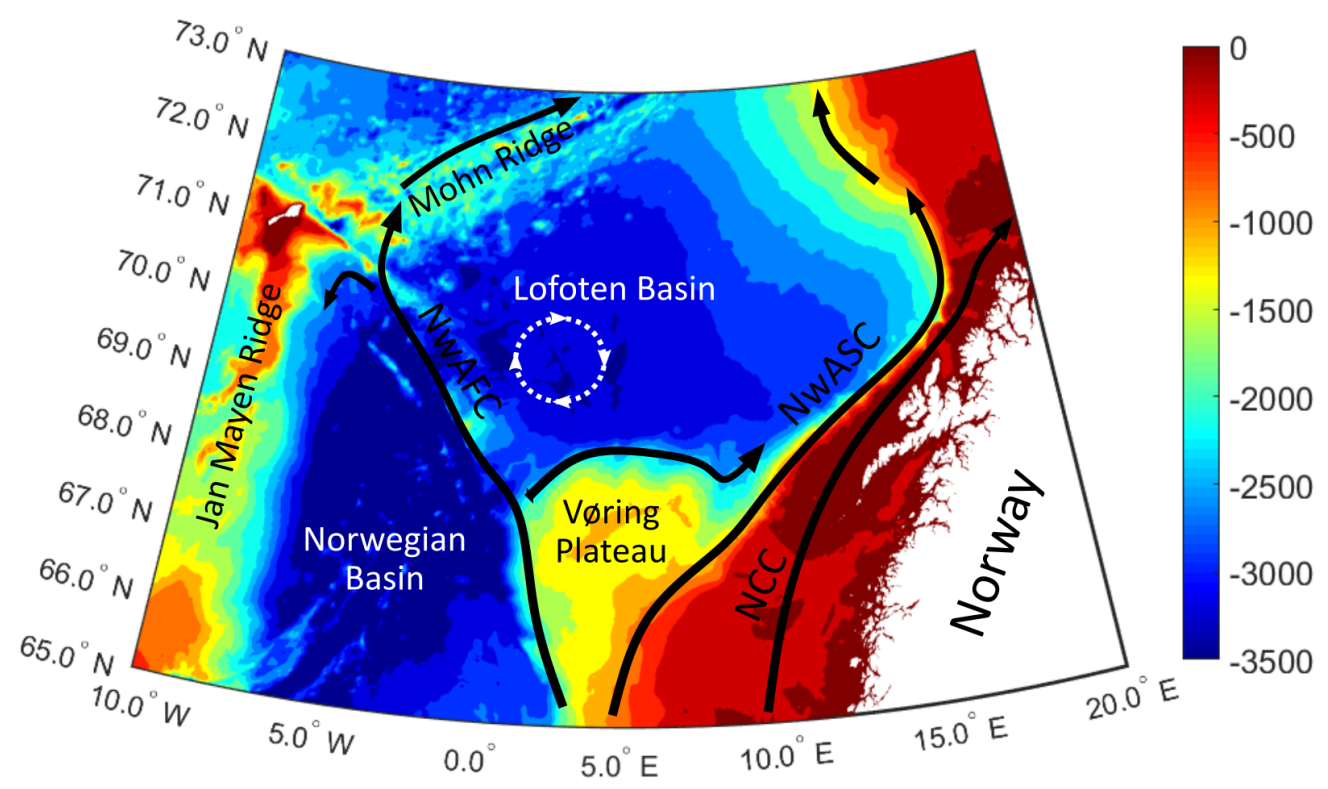

Figure 1. Bottom topography (color) and general circulation (arrows) of the study region. The white circle marks the Lofoten Vortex location. The black lines indicate the main currents. Abbreviations: NCC - Norwegian Coastal Current, NwASC - Norwegian Atlantic Slope Current, NwAFC - Norwegian Atlantic Frontal Current.

ter and thereby of ocean heat content [Björk et al., 2001, and furthermore the most eddy-rich region of the Nordic Seas [e.g., Bloshkina and Ivanov, 2016. Jakobsen et al., 2003, Poulain et al., 1996, Raj et al., 2015, 2016, Volkov et al., 20132015, where large ocean-atmosphere interactions occur [Rossby et al., 2009b.

The most remarkable dynamical phenomenon in the center of the LB is a quasi-permanent anticyclonic eddy known as the Lofoten Vortex (LV), represented by a convective lens of warm and saline water in the 300-1000 $\mathrm{m}$ depth with a horizontal scale of $100 \mathrm{~km}$. The LV extending to a depth of $3250 \mathrm{~m}$ was discovered during the hydrographic studies of the Arctic and Antarctic Research Institute in 1970s-1980s [Alexeev et al., 1991; Ivanov and Korablev, 1995a, 1995b, and it is currently one of the most studied vortexes in the World Ocean. Since then, a number of hydrographic studies have confirmed the existence of the LV using in situ data [Alexeev et al., 2016, Bashmachnikov et al., 2017, Fer et al., 2018, Koszalka et al., 2011; Rossby et al., 2009a; Søiland and Rossby, 2013; Yu et al., 2017], satellite altimetry [Raj et al., 2015, 2016, and ocean model data [Köhl, 2007; Volkov et al., 2013 2015. Belonenko et al. 2014 indicate the po- sition of the LV according to hydrodynamic modeling data in an area bounded by $69^{\circ}-70^{\circ} \mathrm{N}$ and $3^{\circ}-5^{\circ} \mathrm{E}$.

Another remarkable feature of the LB is the high intense synoptic-scale variability of mesoscale eddies. The region of the LB well recognized as an area of energetic mesoscale activity, and also has substantial heat loss to the atmosphere [Raj et al., 2016. Richards and Straneo, 2015. Rossby et al., 2009a Yu et al., 2017. Similar to other parts of the World Ocean, both anticyclonic eddies (ACEs) and cyclonic eddies (CEs) characterize the mesoscale eddy activity of the Lofoten Basin [e.g., Köhl, 2007. Raj et al., 2015, 2016, Zinchenko et al., 2019]. The LB eddies extract volume from the warm and salty NwAC and further redistribute it over the basin, thereby strongly affect the thermohaline structure of the basin. It also modulates the amount of heat and salt carried by the NwAC poleward. Recent observations and modeling studies have provided evidence that eddies reaching the center of the LB are the main mechanism maintaining the permanent LV [Köhl, 2007, Raj et al., 2015; Volkov et al., 2015. Temperature and salinity (T/S) anomalies inside individual eddies tend to move together with the eddies because of advective trapping of 
interior water parcels, thus eddy movement causes heat and salt transports [Belonenko et al., 2018].

A large-scale cyclonic circulation is formed in the LB due to the conservation of potential vorticity. Volkov et al. [2013] analyzed satellite altimetry maps in the Norwegian Sea and revealed a time-averaged cyclonic wavelike propagation of the synoptic-scale SSH anomalies around the center of the LB. They identified dipole and quadrupole wavelike modes of propagation and demonstrated that these modes are largely responsible for the observed amplification of SSH variability in the center of the LB. The velocities of these wavelike structures range from about 2 to $10 \mathrm{~km} /$ day, and their wavelengths are about $500 \mathrm{~km}$. Focusing on the eddy generation from the NwASC, Isachsen 2015 investigated the baroclinic instability of the slope current using an eddy-resolving numerical ocean model. He found that the fastest unstable growth takes place in the steepest part of the continental slope off the eastern Lofoten Basin. It is well known that mesoscale eddies are mainly generated by instabilities of the mean flow [Isachsen, 2015. Zhmur, 2011, or by external forcing such as fluctuating winds [Volkov and $F u, 2008$. It is an obvious fact, that mesoscale eddies are present everywhere in the LB and in all seasons. At the same time, seasonal variability strongly influence their number and thermohaline characteristics. The goal of this study is to examine seasonal variability of the number and the characteristics in the LB using satellite altimetry data and GLORYS reanalysis. Satellite altimetry data of sea surface height anomaly are used to track individual eddies, and co-located vertical profiles are used to study temperature and salinity $(\mathrm{T} / \mathrm{S})$ characteristics.

\section{Data}

Applications of satellite altimetry in the Earth Science are very broad [Lebedev, 2013]. We use the "Mesoscale Eddy Trajectory Atlas Product" available at https://www.aviso.altimetry.fr. This dataset is derived from altimetry data (sea surface height, SSH) using the eddy identification and tracking algorithm [Chelton et al., 2011]. The algorithm distinguishes isolated eddies on daily maps, then a tracking process is applied to study the move of eddy water mass. All data is stored in one file that contains several fields like eddy radius, eddy amplitude, eddy rotation velocity, rotation type, time of observation, ID of the track and some other fields. Eddies are detected from the multimission altimetry datasets, with location each day for the whole altimetry period (1993-ongoing). This algorithm is based on the division of the analyzed field of sea level anomalies with a discreteness of 1 day in time and 1 pixel in space (squares with edge size of $0.25^{\circ}$ ), with the subsequent selection of mesoscale eddies. The algorithm identifies eddies as clusters of pixels (maximum size of eddy is 2000 pixels) that satisfy a specific set of criteria (compactness, the presence of an extremum of sea level anomalies within this cluster, and the consistency of the values of anomalies within the contour of this cluster with its extremum). Thus, we use information on the following parameters for the period 1993-2017:

- amplitude $(\mathrm{cm})$ determined as the difference between the extremum value of sea level anomaly inside the closed contour of SSH and the average value of sea level anomaly outside this contour. Amplitude is positive both for cyclonic and anticyclonic eddies;

- radius $(\mathrm{km})$ defined as the radius of the circle, the area of which equals the area of the outermost closed contour where the orbital velocity of the vortex is maximum;

- orbital velocity $(\mathrm{cm} / \mathrm{s})$ determined as the value of the average geostrophic velocity of the outermost closed SSH contour;

- lifetime defined as the number of days during which the eddy was observed in the SSH field.

We also use the GLORYS12V1 product of the Global Ocean Physics Reanalysis available at CMEMS (Copernicus Marine Environment Monitoring Services). This is the global ocean eddyresolving $\left(1 / 12^{\circ}\right.$ horizontal resolution and 50 vertical levels) reanalysis for the period 1993-2017. It is based largely on the current real-time global forecasting CMEMS system. The model component is the NEMO platform driven at the surface by ECMWF ERA-Interim reanalysis. Observations are assimilated by means of a reduced-order Kalman filter. Along track altimetry data (Sea Level Anomaly), satellite Sea Surface Temperature, Sea Ice Concentration and in situ tempera- 
Table 1. Seasonal variability of mean mesoscale eddy characteristics in the LB for 1993-2017 based on satellite altimetry

\begin{tabular}{|c|c|c|c|c|c|c|c|c|}
\hline \multirow[b]{2}{*}{ Characteristics } & \multirow{2}{*}{\multicolumn{2}{|c|}{$\begin{array}{l}\text { Winter } \\
\text { ACEs }\end{array}$}} & \multicolumn{2}{|c|}{ Spring } & \multicolumn{2}{|c|}{ Summer } & \multicolumn{2}{|c|}{ Autumn } \\
\hline & & & CEs & $\mathrm{ACEs}$ & CEs & ACEs & CEs & ACEs \\
\hline Amount & 238 & 269 & 232 & 262 & 279 & 275 & 277 & 273 \\
\hline Orbital speed $(\mathrm{cm} / \mathrm{s})$ & 10.4 & 10.6 & 10.9 & 11.1 & 8.5 & 10.4 & 8.7 & 9.6 \\
\hline Amplitude $(\mathrm{cm})$ & 4.8 & 4.9 & 5.0 & 5.4 & 3.8 & 5.1 & 3.9 & 4.7 \\
\hline Lifetime period (days) & 26.6 & 24.3 & 26.2 & 27.9 & 27.0 & 30.4 & 27.1 & 27.6 \\
\hline Radius (km) & 56.8 & 54.5 & 53.1 & 54.8 & 54.6 & 53.9 & 56.0 & 55.8 \\
\hline
\end{tabular}

ture and salinity vertical profiles are jointly assimilated. In addition, a 3D-VAR scheme provides a correction for the slowly-evolving large-scale biases in temperature and salinity.

This product includes files of daily and monthly mean temperature, salinity, currents, sea level, mixed layer depth and ice parameters from the top to the bottom. The global ocean output files are displayed on a standard regular grid at $1 / 12^{\circ}$ (approximatively $8 \mathrm{~km}$ ) and on 50 standard levels. We use data for the period 1993-2017.

\section{Methods and Results}

From the altimetry data of 25 years, 1079 ACEs and 1026 CEs were detected in the LB using the algorithm described by Chelton et al. 2011. The mean characteristics of mesoscale eddies in the LB and their seasonal distribution are displayed in the Table 1. Note that the number of ACEs in winter and in spring are larger than the corresponding numbers of CEs, while there is almost no difference between them in summer and in autumn (CEs even dominate a bit). This means that there are better conditions to form ACEs in the LB in cold seasons, compared to CEs. Another important feature is that the average orbital velocity and amplitude are a bit smaller for CEs than for ACEs in summer and autumn in the LB, while there is no difference in those characteristics in other seasons. The lifetime and the radius have no specific seasonal differences (see Table 1).

To analyze the spatial distribution of mean number of eddies in the LB, we created bins with resolution of $1^{\circ}$ of latitude and longitude, and averaged the values within the bins. Figure 2 indicates in- tense formation of mesoscale eddies of both types in the LB. Figure 2 a demonstrates the number of CEs in different seasons. In winter, the maximum of CEs (more than 30) is characteristic for the eastern part of the LB. It can be explained by the instability of the NwASC, especially in winter. Conversely, the western and north-western parts of the LB are characterized by much lower eddy activity (less than 15 eddies per season). Eddies form and break away at the periphery of the NwASC, from where they move towards the central part of the LB due to its topographical structure [Ivanov and Korablev, 1995b; Köhl, 2007. Volkov et al., 2015. In autumn, this area of the unstable NwASC also stands out with 20-25 CEs, which is the maximum of CEs in the whole LB in autumn. However, in summer there are very small numbers of CEs in this domain, and a bit more of them are in spring.

In summer and in autumn, the maximum number of CEs is also observed in the center of the LB where the quasi-permanent anticyclonic eddy known as the LV is located. This fact seems to be paradoxical at the first glance. It is easy to understand why increased concentration of ACEs (Figure 2b) is characteristic for the area where the LV exists at any seasons. However, many CEs are also located in the center of the LB near the LV (Figure 2a). These cyclonic eddies surrounding the quasi-permanent anticyclonic LV form a powerful ring of the LV (shielded vortex) [Carton, 1992 , Tóth and Házi, 2010. These vortices are localized in the vicinity of two points with centers of $69.5^{\circ} \mathrm{N}$, $4^{\circ} \mathrm{E}$ and $70^{\circ} \mathrm{N}, 2.5^{\circ} \mathrm{E}$ [Zinchenko et al., 2019].

The number of ACEs associated with the intensity of the LV varies significantly at seasonal intervals. The greatest intensity is observed in summer and in autumn, and the lowest is in winter and in 
a)
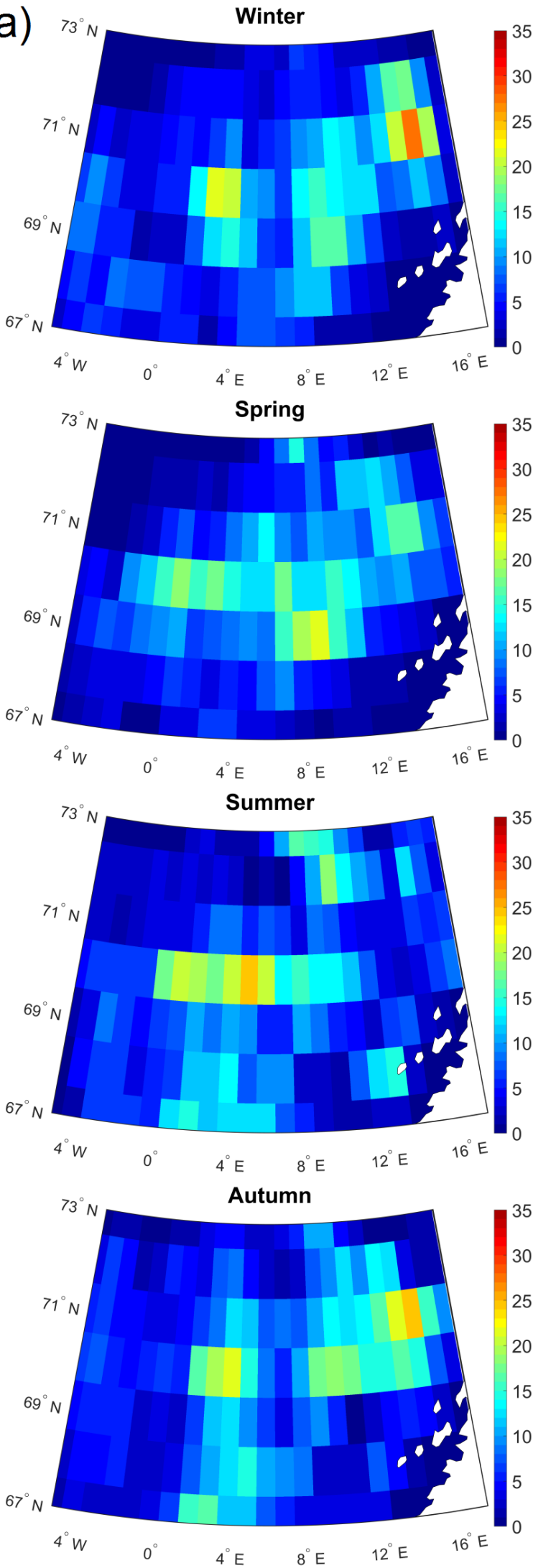
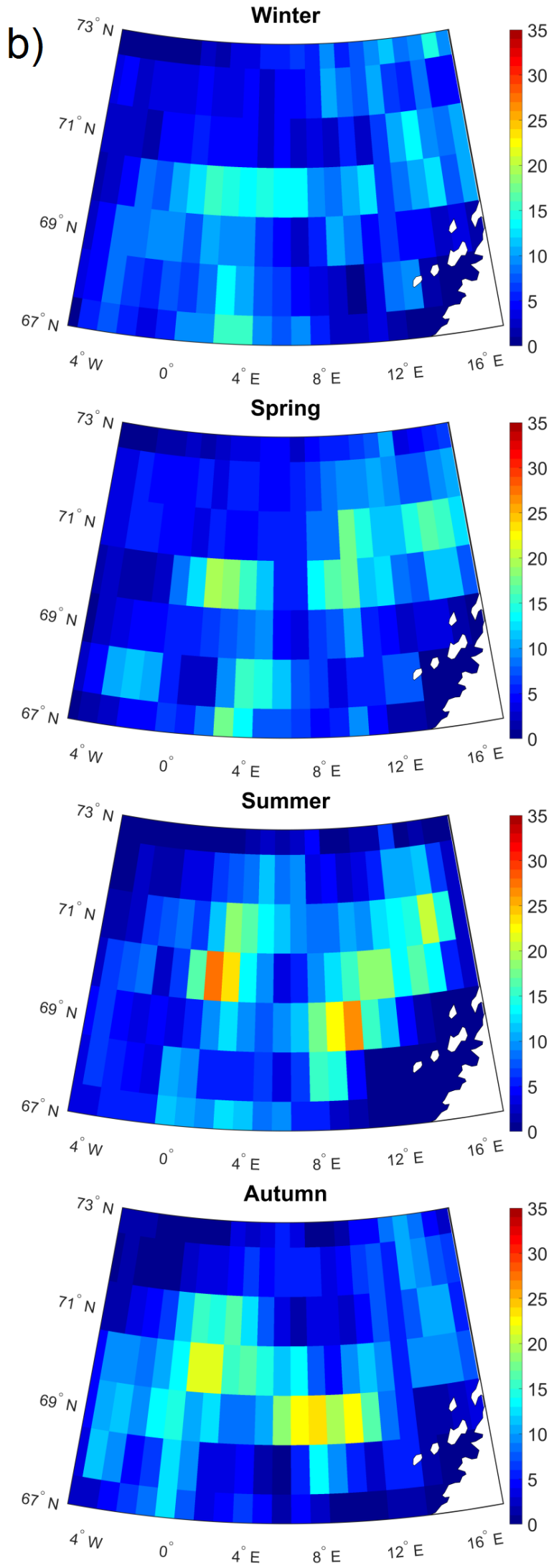

Figure 2. The number of cyclonic (a) and anticyclonic (b) eddies in the LB in different seasons; eddies in every $1^{\circ}$ longitude and latitude bins. 
Table 2. Seasonal variability of time-space averaged thermohaline characteristics of mesoscale eddies in the LB at $450 \mathrm{~m}$ of depth based on the Global Ocean Physics Reanalysis (GLORYS12V1) for 1993-2017

\begin{tabular}{|c|c|c|c|c|c|c|c|c|c|}
\hline \multirow[b]{2}{*}{ Characteristics } & \multirow[t]{2}{*}{ Season } & \multirow{2}{*}{\multicolumn{2}{|c|}{$\begin{array}{l}\text { Winter } \\
\text { ACEs }\end{array}$}} & \multicolumn{2}{|c|}{ Spring } & \multicolumn{2}{|c|}{ Summer } & \multicolumn{2}{|c|}{ Autumn } \\
\hline & & & & CEs & ACEs & CEs & $\mathrm{ACEs}$ & CEs & $\mathrm{ACEs}$ \\
\hline$T\left({ }^{\circ} \mathrm{C}\right)$ & & 3.56 & 3.98 & 3.58 & 4.08 & 3.77 & 4.20 & 4.17 & 4.30 \\
\hline$S$ & & 35.06 & 35.07 & 35.05 & 35.08 & 35.06 & 35.08 & 35.08 & 35.09 \\
\hline$\sigma\left(\mathrm{kg} / \mathrm{m}^{3}\right)$ & & 27.75 & 27.71 & 27.74 & 27.71 & 27.73 & 27.70 & 27.70 & 27.69 \\
\hline
\end{tabular}

spring (Figure $2 \mathrm{~b})$. Increased number of ACEs in summer (27 eddies per bin) and in autumn (23 eddies per bin) are also observed in the south-eastern part of the LB where the NwASC turns to the northeast. However, there are no similar specific features in winter and in spring.

The considered seasonal features are obviously related to the properties of the NwAC that contributes to the formation of many CEs in winter and in autumn in the north-eastern part of the LB, and also of many ACEs in summer and in autumn in the south-eastern part of the LB. All eddies form on the periphery of the NwAC on topographic heterogeneities that are close to the shelf area.

We suppose that mesoscale eddies in the LB appear in anomalies of thermohaline characteristics. Eddies have a strong barotropic component, and their cores are usually located in a layer of 300 $600 \mathrm{~m}$ with $450 \mathrm{~m}$ in the middle [Fer et al., 2018. Zinchenko et al., 2019. That is why we decided to use horizontal plane at $450 \mathrm{~m}$ of depth, and to study seasonal variability of spatial distribution of thermohaline characteristics along this plane. To do so, we used GLORYS12V1 data at $450 \mathrm{~m}$ depth. Notice that in some cases, cores of subsurface eddies may lie above $450 \mathrm{~m}$. However, since the total number of analyzed eddies is quite big (see Table 1), we assume that the resulting error should not be so significant.

At the first step, we revealed $\mathrm{T} / \mathrm{S}$ profiles of GLORYS12V1 data located inside the identified mesoscale eddies using the "Mesoscale Eddy Trajectory Atlas Product" to find bins with co-located profiles. Thus, we analyzed all $\mathrm{T} / \mathrm{S}$ profiles found inside mesoscale eddies in the LB. Table 2 displays mean $\mathrm{T} / \mathrm{S}$ characteristics of eddies at $450 \mathrm{~m}$ of depth. Potential density $\sigma$ was also obtained using the Thermodynamic Equation of Sea Water 2010 (TEOS-10) [McDougall et al., 2012]. Ta- ble 2 demonstrates that the greatest difference in eddy characteristics is manifested in temperature anomalies, and there is much less difference in salinity and density. This means that the thermal component in eddy formation is more important, compared to the haline component. Another explanation might be related to eddy convective processes in the LB for which thermal factors play a dominant role. The maximum values of timespace averaged temperature are specific for ACEs in summer, and minimum values are for CEs in winter and in spring, when the winter convection usually reaches its maximum [Fedorov et al., 2019].

Next, we calculated anomalies of temperature, salinity and potential density at $450 \mathrm{~m}$ of depth in every bin of $1.0^{\circ}$ longitude and $0.5^{\circ}$ latitude for eddies identified in the LB. If an eddy passed through the bin, we subtracted $\mathrm{T} / \mathrm{S}$ values averaged for the season from $\mathrm{T} / \mathrm{S}$ values averaged for considered year. When we had more than one profile in one bin in the season, we calculated the mean value for the bin. Thus, we obtained and analyzed anomalies of temperature, salinity and potential density derived only for eddies in the LB for different seasons.

First of all, the analysis (not shown) reveals that the greatest anomalies of temperature are in winter, and the smallest ones are in autumn. The winter increase can be explained by winter thermal convection that crucially influences annual regeneration of long-lived mesoscale eddies. Due to the weakened stratification in the center of eddies and vertical inversion of salinity, a relatively insignificant cooling of the surface layer can cause hydrostatic instability in eddies. Convection reaches maximum development by the end of winter or in early spring and leads to an increase of horizontal gradients of thermohaline characteristics [Ivanov and Korablev, 1995a. Fedorov et al., 2019. These processes are also manifested in anomalies of $\mathrm{T} / \mathrm{S}$ 


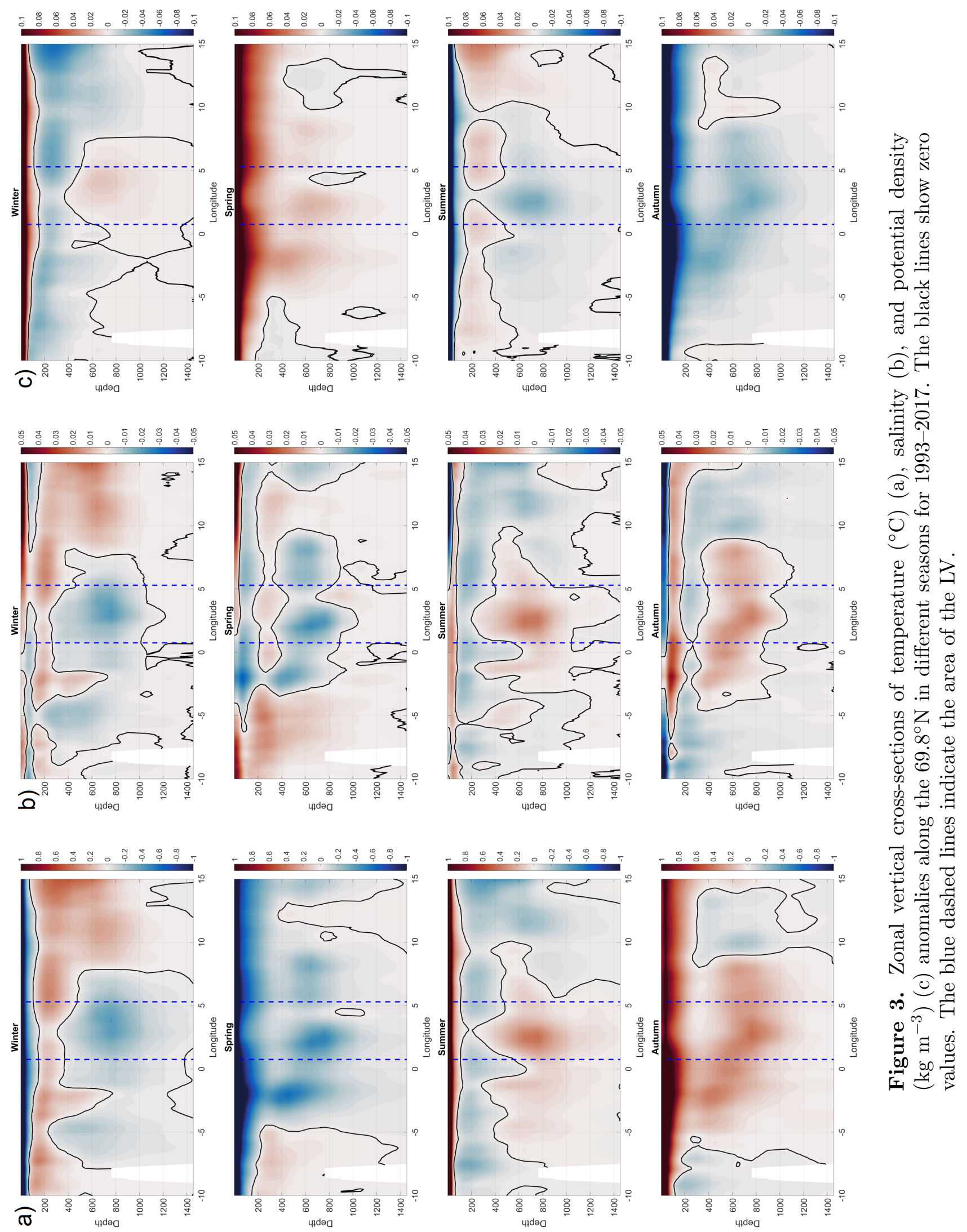


values. The largest negative anomalies of temperature and salinity in CEs are observed at the southern periphery of the LV. They are connected obviously with many CEs that build the shield for the LV (shielded vortex). Salinity anomalies in eddies (not shown) are much smaller. In the whole, this supports the conclusion on dominating thermal component in seasonal variability of eddies in the LB.

The quasi-permanent anticyclonic eddy, LV, is also characterized by a significant seasonal fluctuation of its thermohaline parameters. [Ivanov and Korablev, 1995a noticed much greater variability of temperature, salinity and density parameters in the upper layer of the LV than in the area between the vortex core and the bottom layer. The standard deviation of temperature on a layer between surface and vortex core is much greater than the similar characteristic on a layer between the core and bottom. Ivanov and Korablev 1995a suggested that the very existence of the $L V$ is due to its annual winter thermal regeneration. Point out that the average annual value of temperature in the $\mathrm{LV}$ is $5.45^{\circ} \mathrm{C}$, salinity $35.07 \mathrm{psu}$, and potential density $27.55 \mathrm{~kg} / \mathrm{m}^{3}$ [Ivanov and Korablev, 1995a].

To analyze seasonal variability of thermohaline structure in the area close to the LV from the data of reanalysis GLORYS12V1 for 25-year period, we built a cross-section along $69.8^{\circ} \mathrm{N}$ (that crosses the center of the LV), and estimated T/S anomalies (relative to annual average values). Figure 3 demonstrates the variation of temperature, salinity and potential density depending on the depth, which can help to explain formation of the $\mathrm{LV}$ and its seasonal evolution. In winter, due to the weakened stratification of density in the center of the LV, a deep convection in the LV forms, reaching its maximum in March [Fedorov et al., 2019]. Figure 3 demonstrates predominance of vertical gradients of thermohaline characteristics in the upper part of the LV. In winter, at depths of less than 50 meters, there is a surface layer of water that is colder and saltier than the underlying layers with maximum of positive anomalies of water density, and, consequently, negative buoyancy, contributing to immersion in the intermediate layer and updating the core of the LV during the winter convection. At depths of $200-800 \mathrm{~m}$ in the eastern part of the LB, Atlantic waters are observed. They are characterized by positive anomalies of temperature and salinity and lower values of potential density in comparison to lower layers. In winter, the core of the LV is characterized by negative values of temperature anomalies with a minimum in the core of down to $-0.50^{\circ} \mathrm{C}$. Due to winter convection and penetration of fresh waters into the intermediate layer, the core of the LV is characterized in winter by strong desalination up to $-0.02 \mathrm{psu}$. Due to the presence of cold desalinated water in the LV, the potential density in the core is $0.025-0.05 \mathrm{~kg} / \mathrm{m}^{3}$ in winter, which is higher than the annual mean value (Figure 3a).

In spring, the maximum values of temperature anomalies are recorded, equal to $-0.80^{\circ} \mathrm{C}$ in the center of the LV, which indicates the continuing development of winter convection during this period. Figure $3 \mathrm{~b}$ shows greater salinity in the LV with negative anomalies up to $-0.03 \mathrm{psu}$. The development of winter convection leads to formation of positive potential density anomalies in the core of the $\mathrm{LV}$, reaching values up to $0.05 \mathrm{~kg} / \mathrm{m}^{3}$. In addition, the presence of similar anomalies of thermohaline characteristics near the LV at depths from 200 to $800 \mathrm{~m}$ makes it possible to confirm the existence of secondary convective cores in spring with a vertical depth of about $400-500 \mathrm{~m}$ previously described by Ivanov and Korablev 1995a, 1995b.

During the summer warm-up period, the upper layer of the LV is "cut off" from the surface by a seasonal thermocline, and the vortex takes a distinctive lens-like shape (see Figure 3). In summer and autumn, the temperature in the LV core is higher than the average annual values by $0.6-0.9^{\circ} \mathrm{C}$, whereas the temperature in the surface layer to $100 \mathrm{~m}$ depth is higher than the annual average temperature by $1.5-2.5^{\circ} \mathrm{C}$. As the result, the formation of vertical stable stratification occurs in the summer to autumn period, and it prevents convection into intermediate layers. During this period, intensive salinization of the LV core is observed (the value of salinity anomalies reaches $0.03 \mathrm{psu}$ ). However, due to an increase in temperature, the density anomalies in this period are much lower than annual averaged ones, only up to $-0.06 \mathrm{~kg} / \mathrm{m}^{3}$, and they have the absolute minimum in the core area of the LV. In the second half of the year, viscous relaxation of the LV occurs due to transverse circulation of the LV [Bloshkina and Ivanov, 2016] and turbulent diffusion [Fedorov, 1983, Fer et al., 2018. 


\section{Summary}

Seasonal variability of mesoscale eddies in the LB is manifested both in the seasonal change of number of eddies and in the corresponding change of their thermohaline characteristics. The number of ACEs in winter and in spring is greater than the number of CEs, while there is almost no difference between the numbers in summer and in autumn. In summer and in autumn, the average orbital velocity and amplitude of eddies are a bit smaller for CEs than for ACEs. Maximum number of CEs and ACEs appears in the central and eastern parts of the LB in all seasons, while the western and northwestern parts of the LB is characterized by smaller number of eddies.

The area of the NwAC is more unstable in winter than in other seasons. Maximum number of CEs is also observed in the center of the LB where the quasi-permanent anticyclonic eddy known as the LV is located. The number of ACEs associated with the intensity of the LV varies significantly over seasonal intervals. The greatest intensity is observed in summer and in autumn, and the lowest is in winter and in spring. An increased number of ACEs in summer and in autumn are also observed in the south-eastern part of the LB where the NwASC turns to the northeast.

$\mathrm{T} / \mathrm{S}$ profiles located inside the identified mesoscale eddies at $450 \mathrm{~m}$ of depth provide the quick look at the seasonal variability in the middle of eddy cores. It demonstrates that the greatest differences in eddy characteristics are manifested in temperature anomalies, and much less in salinity and density. The greatest temperature anomalies in eddy cores are observed in winter, and the smallest are in autumn. The largest negative anomalies of temperature and salinity in CEs are noticed on the southern periphery of the LV. There is predominance of vertical gradients of thermohaline characteristics in the upper part of the LV.

Acknowledgments. The authors acknowledge support of Russian Science Foundation (RSF, project No. 18-17-00027).

\section{References}

Alexeev, G. V., M. V. Bagryantsev, P. V. Bogorodsky, V. B. Vasin, P. E. Shirokov (1991), Structure and circulation of water masses in the area of an anticyclonic vortex in the north-eastern part of the Norwegian Sea, Probl. Arctic Antarct., 65, 14-23. (in Russian)

Alexeev, V. A., V. V. Ivanov, I. A. Repina, O. Yu. Lavrova, S. V. Stanichny (2016), Convective structures in the Lofoten Basin based on satellite and Argo data, Izv. Atmos. Ocean. Phys., 52, No. 9, 1064-1077, Crossref

Bashmachnikov, I. L., et al. (2017), On the vertical structure and stability of the Lofoten vortex in the Norwegian Sea, Deep Sea Res. I, 128, 1-27, Crossref

Belonenko, T. V., et al. (2018), Horizontal advection of temperature and salinity by Rossby waves in the North Pacific, International Journal of Remote Sensing, 39, No. 8, 2177-2188, Crossref

Belonenko, T. V., D. L. Volkov, V. K. Ozhigin, Yu. E. Norden (2014), Circulation of waters in the Lofoten Basin of the Norwegian Sea, Vestn. S. Petersbur. Un-ta, 7, No. 2, 108-121.

Björk, G., B. G. Gustafsson, A. Stigebrandt (2001), Upper layer circulation of the Nordic seas as inferred from the spatial distribution of heat and freshwater content, Polar Res., 20, 161-168, Crossref

Bloshkina, E. V., V. V. Ivanov (2016), Convective structures in the Norwegian and Greenland Seas based on simulation results with high spatial resolution, Proceedings of the Hydrometeorological Research Center of the Russian Federation, 361, 146-168.

Carton, X. J. (1992), On the Merger of Shielded Vortices, EPL (Europhysics Letters), 18, No. 8, Crossref

Chelton, D. B., M. G. Schlax, R. M. Samelson (2011), Global observations of nonlinear mesoscale eddies, Prog. Oceanogr., 91, 167-216, Crossref

Fedorov, K. N. (1983), Physical Nature and Structure of Oceanic Fronts, 296 pp. Gidrometeoizdat, Leningrad. (in Russian)

Fedorov, A. M., I. L. Bashmachnikov, T. V. Belonenko (2019), Winter convection in the Lofoten Basin according to ARGO buoys and hydrodynamic modeling, Vestn S. Petersbur. Un-ta, Earth Sciences, 64, No. 3, 491-511. (in Russian)

Fer, I., A. Bosse, B. Ferron, P. Bouruet-Aubertot (2018), The dissipation of kinetic energy in the Lofoten Basin Eddy, J. Phys. Oceanogr., 48, No. 6, 1299-1316, Crossref

Isachsen, P. E. (2015), Baroclinic instability and the mesoscale eddy field around the Lofoten Basin, $J$. Geophys. Res., 120, No. 4, 2884-2903, Crossref

Ivanov, V. V., A. A. Korablev (1995a), Formation and regeneration of the pycnocline lens in the Norwegian Sea, Russ. Meteor. Hydrol., 9, 62-69.

Ivanov, V. V., A. A. Korablev (1995b), Formation 
and regeneration of the pycnocline lens in the Norwegian Sea, Russ. Meteor. Hydrol., 10, 55-62.

Jakobsen, P., M. Ribergaard, D. Quadfasel, T. Schmith, C. Hughes (2003), Nearsurface circulation in the northern North Atlantic as inferred from Lagrangian drifters: Variability from the mesoscale to interannual, J. Geophys. Res., 108, No. C8, 3251-3254, Crossref

Köhl, A. (2007), Generation and stability of a quasi-permanent vortex in the Lofoten Basin, $J$. Phys. Oceanogr., 37, 2637-2651, Crossref

Koszalka, I., J. H. LaCasce, M. K. Andersson, A. Orvik, C. Mauritzen (2011), Surface circulation in the Nordic seas from clustered drifters, Deep Sea Res. I, 58, 468-485, Crossref

Lebedev, S. A. (2013), Satellite altimetry in the Earth Sciences, Modern Problems of Remote Sensing of the Earth From Space, 10, No. 3, 33-49. (in Russian)

McDougall, T. J., D. R. Jackett, F. J. Millero, R. Pawlowicz, P. M. Barker (2012), A global algorithm for estimating Absolute Salinity, Ocean Sci., 8, 1123-1134, Crossref

Mork, K. A., Ø. Skagseth (2010), $\quad$ A quantitative description of the Norwegian Atlantic Current by combining altimetry and hydrography, Ocean Science, 6, 901-911, Crossref

Poulain, P.-M., A. Warn-Varnas, P. P. Niiler (1996), Near-surface circulation of the Nordic seas as measured by Largangian drifters, J. Geophys. Res., 101, No. C8, 18237-18258, Crossref

Raj, R. P., L. Chafik, J. E. Ø. Nilsen, T. Eldevik, I. Halo (2015), The Lofoten Vortex of the Nordic seas, Deep Sea Res. I, 96, 1-14, Crossref

Raj, R. P., J. A. Johannessen, T. Eldevik, J. E. Ø. Nilsen, I. Halo (2016), Quantifying mesoscale eddies in the Lofoten Basin, J. Geophys. Res. Oceans, 121, 4503-4521, Crossref

Richards, C., F. Straneo (2015), Observations of Water Mass Transformation and Eddies in the Lofoten Basin of the Nordic Seas, J. Phys. Oceanography, 45, No. 6, 1735-1737, Crossref

Rossby, T., V. Ozhigin, V. Ivshin, S. Bacon (2009a), An isopycnal view of the Nordic Seas hydrography with focus on properties of the Lofoten Basin, Deep Sea Res. I, 56, No. 11, 1955-1971, Crossref
Rossby, T., M. D. Prater, H. Søiland (2009b), Pathways of inflow and dispersion of warm waters in the Nordic seas, J. Geophys. Res., 114, C04011, Crossref

Skagseth, Ø., A. Slotte, E.K. Stenevik, R. D. M. Nash (2015), Characteristics of the Norwegian Coastal Current during Years with High Recruitment of Norwegian Spring Spawning Herring (Clupea harengus L.), PLoS ONE, 10, No. 12, e0144117, Crossref

Søiland, H., T. Rossby (2013), On the structure of the Lofoten Basin Eddy, J. Geophys. Res., 118, 4201-4212, Crossref

Tóth, G., G. Házi (2010), Merging of shielded Gaussian vortices and formation of a tripole at low Reynolds numbers, Physics of Fluids, 22, 053101, Crossref

Volkov, D. L., L.-L. Fu (2008), The role of vorticity fluxes in the dynamics of the Zapiola Anticyclone, J. Geophys. Res., 113, C11015, Crossref

Volkov, D. L., T. V. Belonenko, V. R. Foux (2013), Puzzling over the dynamics of the Lofoten Basin a sub-Arctic hot spot of ocean variability, Geophys. Res. Lett., 40, No. 4, 738-743, Crossref

Volkov, D. L., A. Kubryakov, R. Lumpkin (2015), Formation and variability of the Lofoten Basin vortex in a high-resolution ocean model, Deep Sea Res. I, 105, 142-157, Crossref

Yu, L.-S., A. Bosse, I. Fer, K. A. Orvik, E. M. Bruvik, I. Hessevik, K. Kvalsund (2017), The Lofoten Basin eddy: Three years of evolution as observed by Seagliders, J. Geophys. Res. Oceans, 122, 6814-6834, Crossref

Zinchenko, V. A., S. M. Gordeeva, Yu. V. Sobko, T. V. Belonenko (2019), Analysis of Mesoscale eddies in the Lofoten Basin based on satellite altimetry, Fundamental and Applied Hydrophysics, 12, No. 3 , 46-54.

Zhmur, V. V. (2011), Physical Nature and Structure of Oceanic Fronts, 384 pp. GEOS, Moscow. (in Russian)

Corresponding author:

T. V. Belonenko, Saint Petersburg State University, Universitetskaya emb. 7-9, 199034, Saint Petersburg, Russia.(btvlisab@yandex.ru) 